\title{
Triptolide inhibits the multidrug resistance in prostate cancer cells via the downregulation of MDR1 expression
}

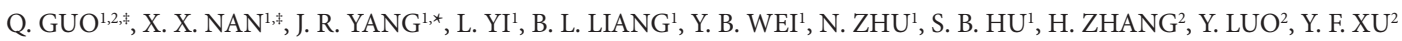 \\ ${ }^{1}$ Department of Urology, Second Xiangya Hospital, Central South University, 410011, Changsha, China; ${ }^{2}$ Department of Urology, The Third \\ Hospital Of Changsha, 410015, Changsha, China \\ ${ }^{*}$ Correspondence: yangjinrui33@163.com \\ ${ }^{*}$ Contributed equally to this work.
}

Received December 11, 2012 / Accepted March 20, 2013

\begin{abstract}
Triptolide (TPL) is a diterpenoid triepoxide derived from the Chinese herb Tripterygium wilfordii and possesses anti-tumor activity against a range of cancer cells. However, the effect of TPL on prostate cancer cells and its potential to overcome multidrug resistance (MDR) have not been explored. Therefore, in this study we used prostate cancer cell line DU145 as the experimental model and established DU145/ADM cell line resistant to adriamycin (ADM). Our results showed that TPL inhibited the proliferation and induced the cell cycle arrest and apoptosis of DU145 cells in a dose and time dependent manner. TPL decreased the levels of Cyclin D1 and anti-apoptotic protein Bcl-2, and increased the levels of pro-apoptotic proteins Fas and Bax. Furthermore, we found that TPL restored the sensitivity DU145/ADM cells to ADM in a dose dependent manner, and this was accompanied by the inhibition of MDR1 expression at both mRNA and protein levels. Taken together, these results provide strong evidence that TPL overcomes MDR in prostate cancer cells by downregulating MDR1 expression, and suggest that TPL is a promising agent for prostate cancer therapy, especially for chemoresistant prostate cancer.
\end{abstract}

Key words: MDR1, multidrug resistance, prostate cancer, triptolide, apoptosis

Prostate cancer is a form of malignancy that frequently develops in older males and is one of the leading causes of cancer death in men. Recently, great progress has been made in the prevention, detection and prognosis of patients with prostate cancer [1-4].

However, prostate cancer is known to exhibit the ability to metastasize to other parts of the body, particularly the bones, and develop resistance to chemotherapy. Therefore, the effective treatment for prostate cancer is still a challenge in the clinic.

Multidrug resistance (MDR) is a common mechanism for tumor cells to overcome the cytotoxicity of a broad spectrum of anticancer agents, and remains a major obstacle to cancer chemotherapy. P-glycoprotein, also known as multidrug resistance protein 1 (MDR1), is encoded by mdr1 gene and plays important role in $\operatorname{MDR}[5,6]$. Accumulating evidence has suggested that MDR1 is a potential target to overcome MDR and increase the sensitivity of tumor cells to chemotherapy. Interestingly, phytochemicals derived from Chinese herbs emerged as new candidates of P-glycoprotein inhibitors and showed promise in cancer therapy to overcome MDR [7].
Triptolide (TPL) is a diterpenoid triepoxide extracted from the Chinese herb Tripterygium wilfordii Hook $\mathrm{f}$. which has been used for centuries as Chinese traditional herbal remedies for autoimmune and inflammatory diseases [8]. Recent studies have shown that TPL possesses anti-tumor activity by inhibiting the proliferation and inducing the apoptosis in a variety of cancer cells including prostate cancer cells [9-12]. However, the effect of TPL on drug-resistant prostate cancer cells and its potential to overcome MDR have not been explored. Therefore, in this study we used prostate cancer cell line DU145 as the experimental model and established DU145/ADM cell line resistant to adriamycin (ADM). We examined the effects of TPL on the proliferation and apoptosis of DU145 cells, and MDR in DU145/ADM cells.

\section{Materials and methods}

Cells and cell culture. The human prostate cancer cell line DU145 was obtained from the Institute of Biochemistry and Cell Biology, Chinese Academy of Sciences (Shanghai, 
China) and cultured in RPMI-1640 medium (Gibco, USA) supplemented with $10 \%$ fetal calf serum (Hyclone, USA) at $37^{\circ} \mathrm{C}$ in a humidified incubator with $5 \% \mathrm{CO}_{2}$.

Establishment of ADM resistant cell line DU145/ADM

DU145/ADM cell line resistant to adriamycin was established as follows. Briefly, DU145 cells in the exponential phase of growth were exposed to adriamycin (Zhejiang Hisun Pharmaceutical, Hangzhou, China) at the concentration of 50 $\mathrm{ng} / \mathrm{ml}$ for 1 month. The adriamycin-resistant DU145/ADM cell line was established three months after the drug treatment was initiated and then maintained in a drug-free medium and subcultured for at least 3 times.

MTT assay. MTT assay was performed to examine cell proliferation using a method described previously [13]. Briefly, DU145 or DU145/ADM cells were incubated in 96-well plates at the density of $2 \times 10^{4}$ cells/well and treated with different concentrations of TPL (Chengdu Biopurity Phytochemicals, Chengdu, China) for different time. The inhibition of cell proliferation was calculated as follows: Inhibition ratio $=($ mean OD of control-mean OD of experiment)/mean OD of control x 100\%. $\mathrm{IC}_{50}$ was calculated with Prism GraphPad 6.0.

Cell cycle and apoptosis analysis. Flow cytometry analysis was performed to assess the cell cycle phase distribution and apoptosis. DU145 cells were incubated in 6-well plates at the density of $5 \times 10^{5}$ cells/well and treated with different concentrations of TPL for different time. The cells were harvested and fixed in $70 \%$ ethanol overnight. Next the cells were washed with PBS, resuspended in PBS and treated with RNase A $(100 \mathrm{mg} / \mathrm{ml} \mathrm{PBS})$ at $37^{\circ} \mathrm{C}$ for $30 \mathrm{~min}$. Then the cells were resuspended in propidium iodide $(50 \mathrm{mg} / \mathrm{ml} \mathrm{PBS})$ and stained at room temperature for $30 \mathrm{~min}$. The samples were analyzed using FACSort flow cytometry (Beckman Coulter) within $1 \mathrm{~h}$ after staining. The data were analyzed using Cell Quest software. Each experiment was repeated three times.

RT-PCR. DU145 or DU145/ADM cells were seeded in 6well plates and cultured overnight. The cells were then treated with TPL at different concentrations $(20,40,80 \mathrm{ng} / \mathrm{ml})$ for $72 \mathrm{~h}$, washed twice with ice-cold PBS. Total RNA was extracted from the cells using Trizol reagent (Invitrogen, Carlsbad, CA, USA) according to the manufacturer's protocol. cDNA was prepared using M-MLV reverse transcriptase (Promega, Madison, WI, USA). PCR primers for MDR1 and $\beta$-actin were as follows: MDR1, sense 5'- AGA AGG TTC TGG GAA GA TCGC-3', antisense 5'-ATG TCC TTT TCC AGC ACC TC-3', product size 286 bp; $\beta$-actin, sense 5 ' - TGT TTG AGA CCT TCA ACA CCC-3', antisense 5'-AGC ACT GTG TTG GCG TAC AG-3', product size $529 \mathrm{bp}$. PCR reaction was performed using the EX Tag (TaKaRa, Dalian, China Japan) and the conditions were: denaturation at $98^{\circ} \mathrm{C}$ for $10 \mathrm{~s}$, annealing at $55^{\circ} \mathrm{C}$ for $30 \mathrm{~s}$, and elongation at $72^{\circ} \mathrm{C}$ for $1 \mathrm{~min}$. PCR products were visualized by electrophoresis on $1.2 \%$ agarose gel stained with ethidium bromide. Image was obtained by the BIO-RAD Gel Doc and analyzed with Gel-Pro Analyzer 4.5.

Western blot analysis. DU145 or DU145/ADM cells were seeded in 6-well plates and cultured overnight. The cells were then treated with TPL at different concentrations (20,40, $80 \mathrm{ng} / \mathrm{ml}$ ) for $72 \mathrm{~h}$, washed twice with ice-cold PBS. Lysate was extracted from the cells using RIPA Lysis Buffer and the protein concentration of the lyaste was measured using a BCA Protein Assay Kit (Pierce, USA). Equal amount of lysate (50 ug protein) was separated by $12 \%$ SDS-PAGE and transferred onto PVDF membranes (Pierce, USA). The membranes were blocked with $5 \%$ nonfat milk for $1 \mathrm{~h}$ at room temperature and incubated overnight at $4^{\circ} \mathrm{C}$ with primary antibodies against MDR1, Cyclin D1, Bcl-2, Bax, Fas, cleaved Caspase-3 or $\beta$-actin (Santa Cruz, USA). The membranes were washed 3 times for $15 \mathrm{~min}$ in TBS containing $0.05 \%$ Tween-20, and then incubated with horseradish peroxidase conjugated secondary antibodies (Santa Cruz, USA) at room temperature for $1 \mathrm{~h}$. Positive immunereactions were detected using Super Signal West Pico Chemiluminescent Substrate (Thermo, USA) and exposed to X-ray films.

Statistical analysis. Data were expressed as the mean $\pm S D$ and analyzed using the SPSS version 12 statistical analysis package (SPSS Inc., Chicago, IL, USA). $\mathrm{P}<0.05$ was accepted as statistically significant.

\section{Results}

TPL inhibits the proliferation and induces the apoptosis of DU145 cells. First we examined the effects of TPL on the proliferation and apoptosis of prostate cancer cells. We treated DU145 cells with different concentrations of TPL (20,40, $80 \mathrm{ng} / \mathrm{ml}$ ) for $24 \mathrm{~h}, 48 \mathrm{~h}$, or $72 \mathrm{~h}$ and performed MTT assay. The results showed that TPL inhibited the proliferation of DU145 cells in a dose and time dependent manner (Fig. 1). The IC50 of TPL for DU145 cells at $24 \mathrm{~h}, 48 \mathrm{~h}$ and $72 \mathrm{~h}$ were 40, 27 and $17 \mathrm{nmol} / \mathrm{L}$, respectively. Since TPL exhibited the most significant inhibitory effects on DU145 cell proliferation

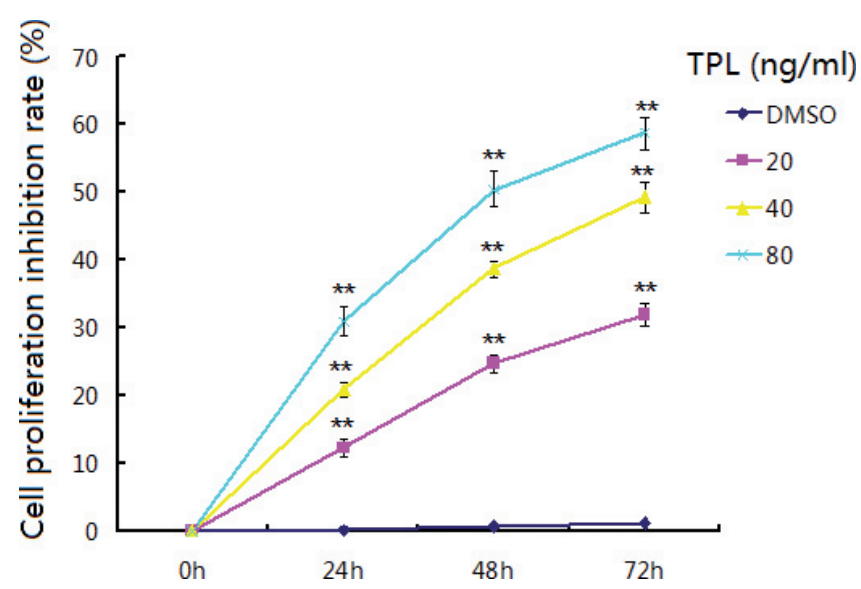

Figure 1. TPL inhibits the proliferation of DU145 cells. DU145 cells were treated with 20,40 , or $80 \mathrm{ng} / \mathrm{ml}$ TLP for $24 \mathrm{~h}, 48 \mathrm{~h}$ or $72 \mathrm{~h}$, and cell viability was examined by MTT assay. DU145 cells treated with DMSO were used as control. Each point represented the mean \pm SD of triplicates. Each experiment was performed in three times. ${ }^{*} \mathrm{P}<0.01$ versus $0 \mathrm{~h}$. 

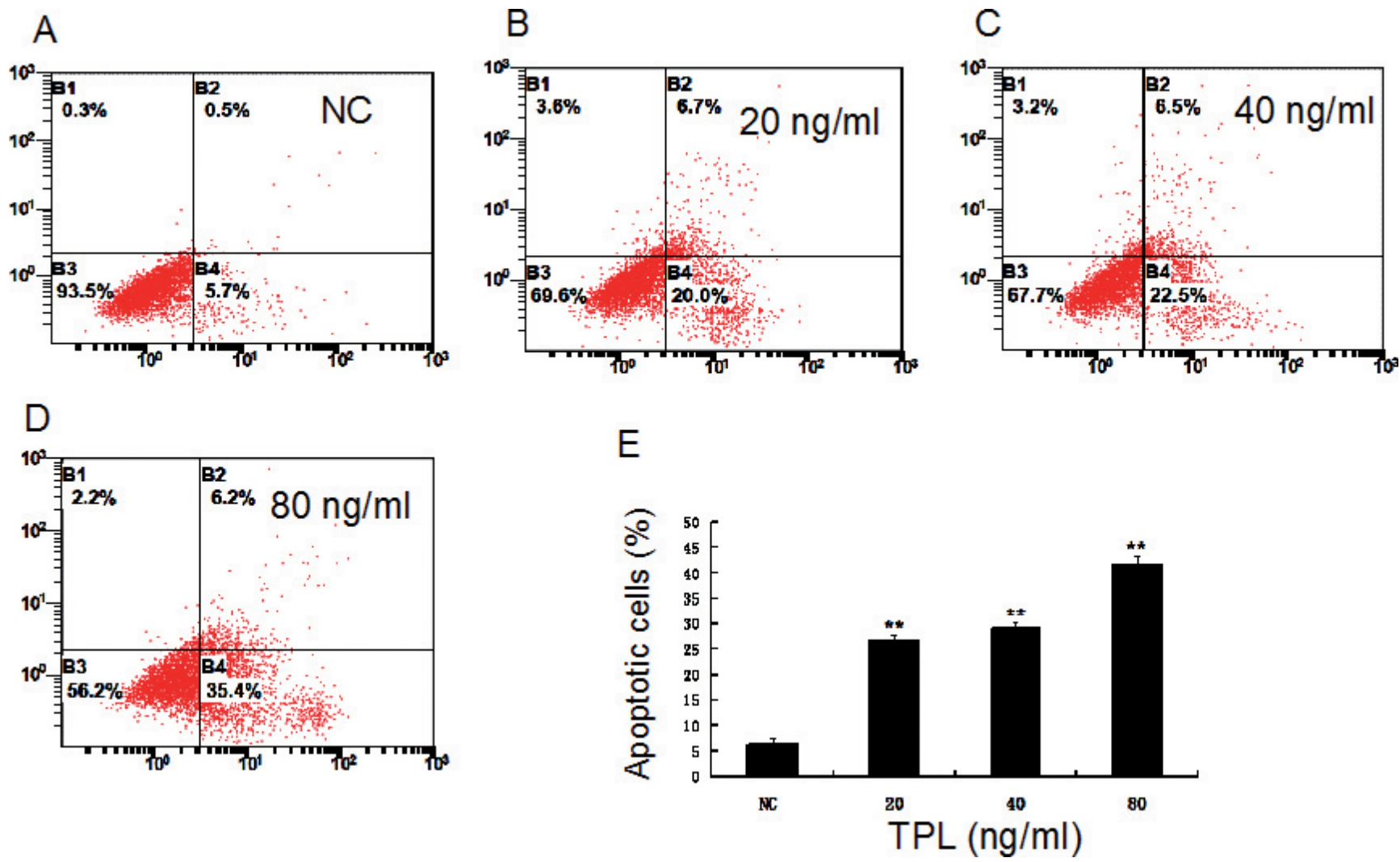

Figure 2. TPL induces the apoptosis of DU145 cells. DU145 cells were treated with DMSO (NC), 20, 40 or $80 \mathrm{ng} / \mathrm{ml}$ TPL for $72 \mathrm{~h}$, and apoptosis was detected by flow cytometry analysis. A-D: Representative flow histograms showing the apoptosis of DU145 cells treated with TPL at the indicated concentration. E. Quantization of the percentage of apoptotic cells. ${ }^{* *} \mathrm{p}<0.01$ versus NC.

after treatment for $72 \mathrm{~h}$, we chose $72 \mathrm{~h}$ as the time point for the following experiments.

Next we performed flow cytometry analysis to examine the apoptosis of DU145 cells treated by TPL. Flow cytometry analysis showed that TPL induced the apoptosis of DU145 cells in a dose dependent manner at $72 \mathrm{~h}$ (Fig. 2). The apoptosis rate of DU145 cells after treatment with $0,20,40$, and $80 \mathrm{ng} / \mathrm{ml}$ TPL was $6.3 \pm 0.97 \%, 26.7 \pm 1.08 \%, 29.0 \pm 1.21 \%$ and $41.6 \pm 1.66 \%$, respectively, and the differences in apoptosis rate between control and TPL treated cells were significant $(\mathrm{p}<0.05)$.

We further examined the cell cycle phase distribution of DU145 cells after treatment with $0,20,40$, and $80 \mathrm{ng} / \mathrm{ml} \mathrm{TPL}$ for $72 \mathrm{~h}$. Flow cytometry analysis showed that TPL induced $S$ phase arrest in DU145 cells in a dose dependent manner (Fig. 3). Collectively, these data suggest that TPL inhibits prostate cancer cell growth by inducing $S$ phase arrest and apoptosis.

TPL modulates the expression of cell cycle and apoptosis associated proteins in DU145 cells. To explore the molecular mechanism by which TPL induces the cell cycle arrest and apoptosis of DU145 cells, DU145 cells were treated with 20, 40 , or $80 \mathrm{ng} / \mathrm{ml} \mathrm{TPL}$ for $72 \mathrm{~h}$ and subjected to Western blot analysis. The results showed that TPL decreased the protein level of cyclin D1. For apoptosis associated proteins, TPL increased the protein level of Fas and Bax, and decreased the protein level of $\mathrm{Bcl}-2$. In addition, the protein level of cleaved Caspase-3 was increased after TPL treatment, indicating increased apoptosis (Fig. 4). Taken together, these results suggest that TPL modulates the expression of cell cycle and apoptosis associated proteins to regulate cell cycle and apoptosis of prostate cancer cells.

TPL overcomes MDR in DU145/ADM cells. To investigate the effects of TPL on MDR, we treated DU145/ADM cells with 20 , 40 , or $80 \mathrm{ng} / \mathrm{ml} \mathrm{TPL}$ together with $10,20,30,40$ or 50 $\mathrm{ng} / \mathrm{ml} \mathrm{ADM}$ for $72 \mathrm{~h}$ simultaneously. The results demonstrated that TPL increased the sensitivity of DU145/ADM cells to ADM induced cell proliferation inhibition in a dose and time dependent manner (Fig. 5). These data suggest that TPL may overcome MDR in prostate cancer cells.

TPL inhibits MDR1 expression in DU145/ADM cells. To elucidate the molecular mechanisms by which TPL overcomes MDR in prostate cancer, we examined the expression of MDR1 in DU145/ADM cells. As expected, RT-PCR and Western blot analysis showed that the expression of MDR1 at both mRNA and protein levels in drug resistant DU145/ADM cells was much higher than in DU145 cells (Fig. 6). However, when DU145/ADM cells were treated with TPL for $72 \mathrm{~h}$, the expres- 
A

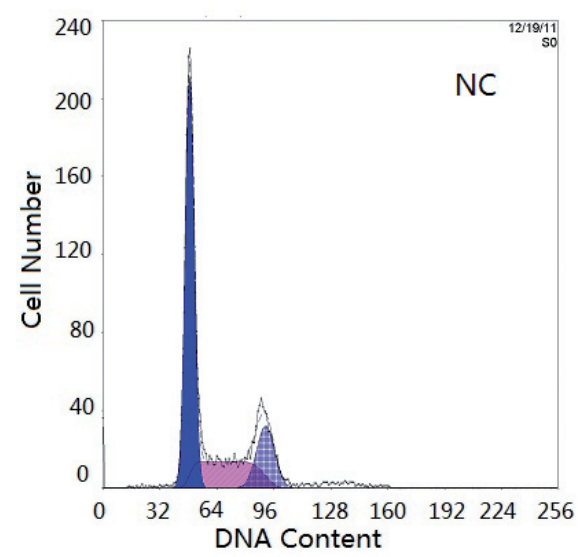

D

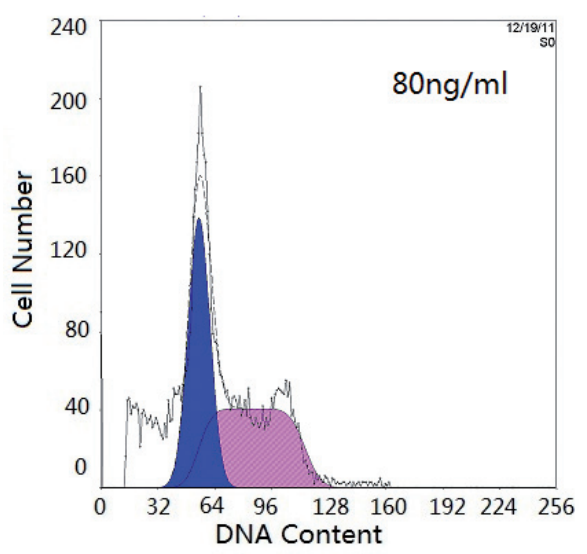

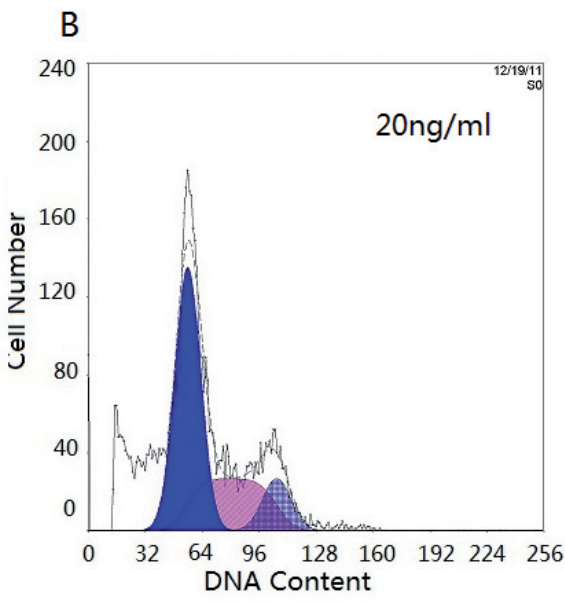
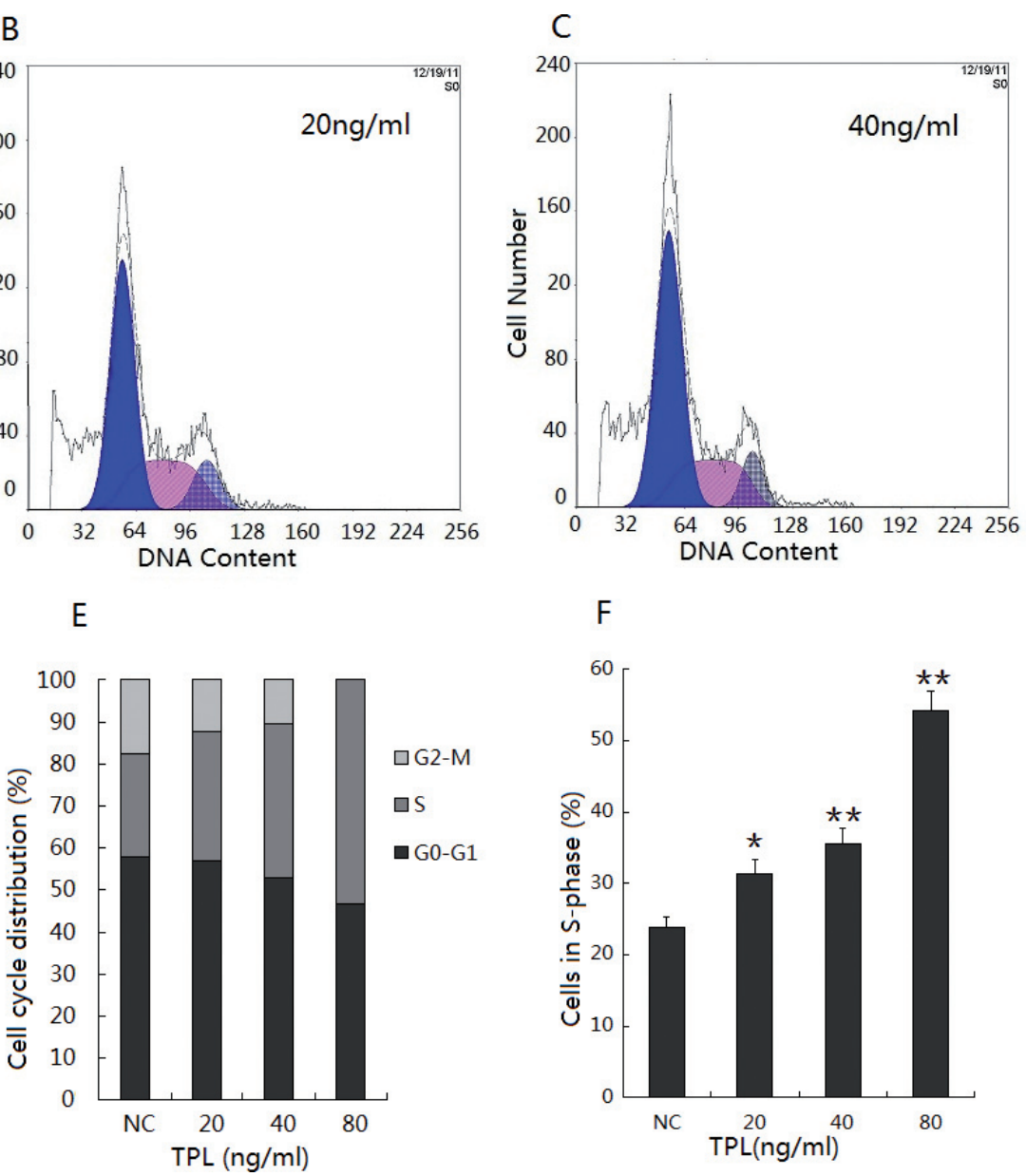

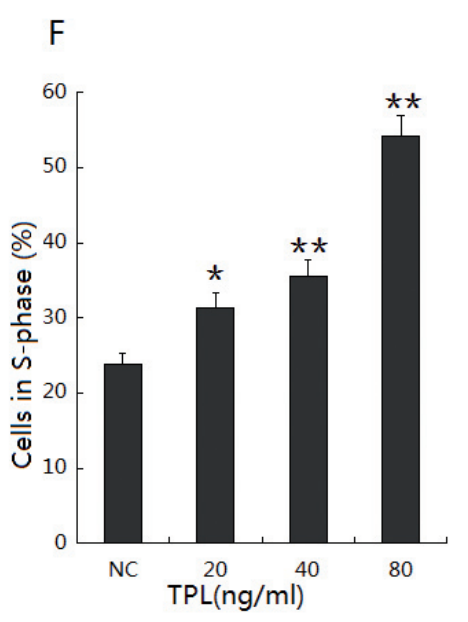

Figure 3. TPL induces the S phase arrest of DU145 cells. DU145 cells were treated with DMSO (NC), 20, 40 or $80 \mathrm{ng} / \mathrm{ml} \mathrm{TPL} \mathrm{for} 72 \mathrm{~h}$, and cell cycle distribution was detected by flow cytometry analysis. A-D: Representative flow histograms showing the cell cycle profiling of DU145 cells treated with TPL at the indicated concentration. E. Quantization of the cells in different phase. F. Quantization of the cells in $S$ phase. ${ }^{\star} p<0.05$ versus NC. ${ }^{* *} p<0.01$ versus NC.

sion of MDR1 at both mRNA and protein levels was decreased in a dose dependent manner (Fig. 6). Taken together, these results indicate that MDR1 overexpression contributes to MDR in prostate cancer cells and TPL overcomes MDR in prostate cancer cells by inhibiting the expression of MDR1.

\section{Discussion}

Chemotherapy has been widely used for the treatment of cancer and encouraging results have been achieved in some circumstances [13-15]. However, MDR has become one of the major problems for the effective treatment of tumors with chemotherapeutic agents, which is mainly resulted from the expression of transporters that remove the chemotherapeutic agents from the cytoplasm. In particular, the transporter P-glycoprotein encoded by the multidrug resistance 1 gene $\mathrm{mdr} 1$ is one of the most important mechanisms that contribute to MDR $[5,6]$. Interestingly, phytochemicals derived from Chinese herbs have shown promise in overcoming MDR in cancer therapy [7].

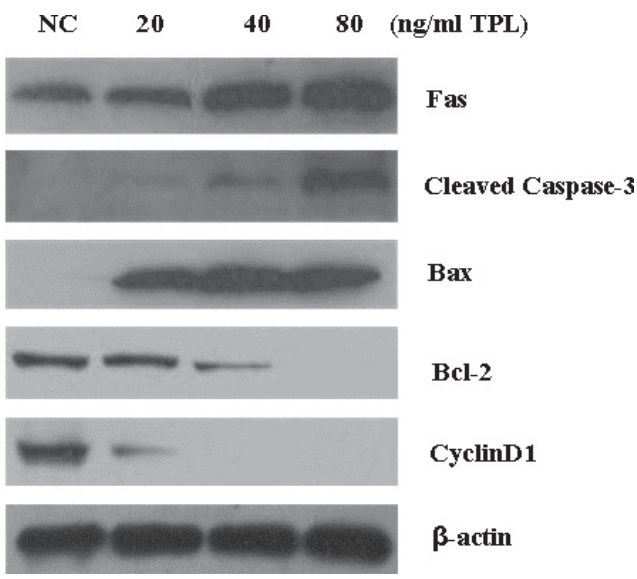

Figure 4. TPL modulates the expression of cell cycle and apoptosis associated proteins in DU145 cells. DU145 cells were treated with DMSO (NC), 20,40 , or $80 \mathrm{ng} / \mathrm{ml}$ TPL for $72 \mathrm{~h}$ and subjected to Western blot analysis. Shown were representative blots from three independent experiments with similar results. $\beta$-actin was used as loading control. 


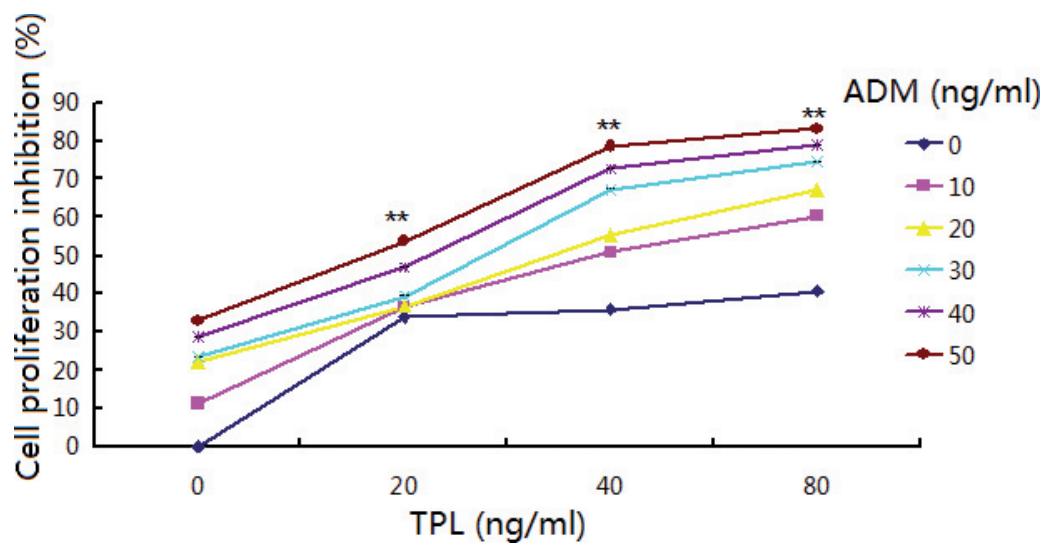

Figure 5. TPL overcomes MDR in DU145/ADM cells. DU145/ADM cells were treated with $0,20,40$, or $80 \mathrm{ng} / \mathrm{ml}$ TPL together with $10,20,30,40$ or $50 \mathrm{ng} / \mathrm{ml}$ ADM for $72 \mathrm{~h}$ simultaneously. The cell viability was examined by MTT assay. Each point represented the mean \pm SD of triplicates. Each experiment was performed in three times. ${ }^{* *} \mathrm{P}<0.01$ versus $0 \mathrm{ng} / \mathrm{ml}$ TPL.

A

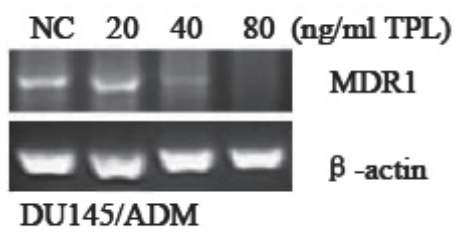

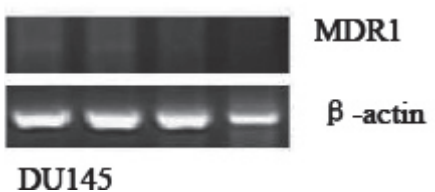

B

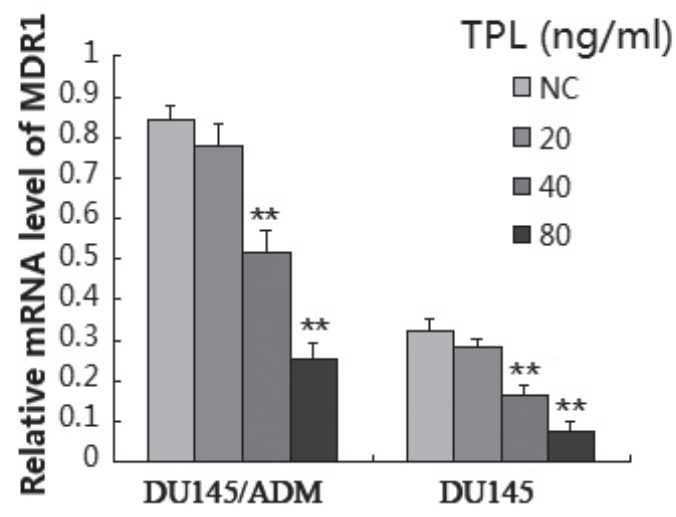

$\mathrm{C}$
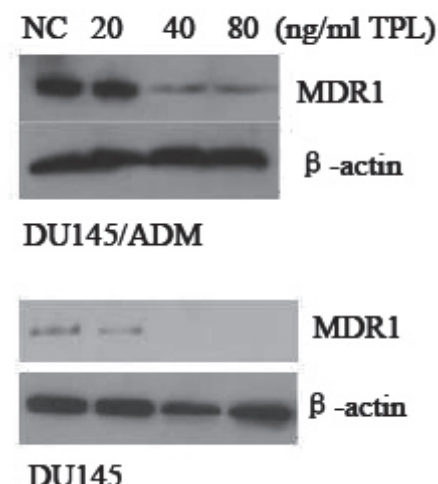

Figure 6. TPL inhibits MDR1 expression in DU145/ADM cells. A. DU145 and DU145/ADM cells were treated with DMSO (NC), 20, 40, or 80 ng/ml TPL for $72 \mathrm{~h}$, the mRNA level of MDR1 was determined by RT-PCR analysis. B. Quantization of relative mRNA level of MDR1. Data were shown as mean \pm SD of three independent experiments. $\beta$-actin was used as internal control. ${ }^{*} p<0.01$ vs. corresponding NC. C. DU145 and DU145/ADM cells were treated with DMSO (NC), 20, 40, or $80 \mathrm{ng} / \mathrm{ml}$ TPL for $72 \mathrm{~h}$, the protein level of MDR1 was determined by Western blot analysis. Shown were representative blots from three independent experiments with similar results. $\beta$-actin was used as loading control.

In this study, we first investigated the effects of TPL on prostate cancer cell proliferation and apoptosis. Our results showed that TPL inhibits the proliferation and induces the apoptosis of DU145 cells, consistent with previous studies which showed that TPL possesses anti-tumor activity by inhibiting the proliferation and inducing the apoptosis in cancer cells [9-12]. Flow cytometry analysis showed that TPL induced $S$ phase arrest in DU145 cells in a dose dependent manner. Thus we propose that TPL inhibits prostate cancer cell growth by inducing $S$ phase arrest and apoptosis.

Next we examined the effects of TPL on the expression of cell cycle and apoptosis associated proteins in DU145 cells. Our results showed that TPL decreased the protein level of Cyclin D1. Cyclin D1 serves as an active switch in the regu- lation of cell cycle and increased cyclin D1 synthesis would promote continued cell cycle progression [16]. As expected, reduced intracellular cyclin D1 level after TPL treatment would hinder the cell cycle progression and lead to $S$ phase arrest in DU145 cells. On the other hand, our results showed that TPL increased the levels of pro-apoptotic proteins such as Fas and Bax, and decreased the level of anti-apoptotic protein Bcl-2. The cleavage of pro-Caspase- 3 is a marker of the execution of apoptosis [17]. Our finding that TPL increased the level of cleaved Caspase- 3 serves as additional evidence that TPL modulates the expression of apoptosis associated proteins to promote the apoptosis of prostate cancer cells.

Finally, we established drug resistant DU145/ADM cells by treating parent DU145 cells with ADM. We found that after 
TPL treatment, DU145/ADM cells recovered the sensitivity to $\mathrm{ADM}$ treatment in a dose dependent manner, and this was accompanied by decreased MDR1 expression at both mRNA and protein levels. Taken together, these results provide strong evidence that TPL overcomes MDR in prostate cancer cells by downregulating the expression of MDR1. In fact, TPL was shown to decrease the expression of MDR in $\mathrm{KB}$ cancer cells [18]. Furthermore, TPL was capable of inhibiting the transcriptional activity of MDR1 promoter, and thus reversed adriamycin resistance in leukemia cells via modulation of P-glycoprotein expression [19]. A recent study reported that perifosine, anew Akt inhibitor, could reverse MDR partially via the downregulation of MDR1 expression in MCF-7/ADM breast cancer cells [20]. Notably, TPL exhibited the ability to inactivate Akt in cancer cells [21]. Therefore, we postulate that TPL may inhibit PI3K/Akt pathway to downregulate MDR1 expression. Further studies are needed to elucidate the molecular mechanisms by which TPL suppresses the expression of MDR1.

Interestingly, a previous study showed that the monoterpenoids extracted from the essential oil of Zanthoxyli fructus could inhibit P-gp (MDR1) directly [22]. TPL is a diterpenoid triepoxide extracted from the herb Tripterygium wilfordii and has a molecular structure similar to the monoterpenoids. Therefore, it remains to be determined whether TPL has the ability to inhibit the function of MDR1, which would provide new insight into the action of TPL to overcome MDR in cancer cells.

In conclusion, our data demonstrate that TPL inhibits the proliferation and induces the apoptosis of prostate cancer cells. Most importantly, TPL could reverse MDR1 mediated MDR in ADM resistant prostate cancer cells via the downregulation of MDR1 expression. These results suggest that TPL is a promising agent for prostate cancer therapy, especially for chemoresistant prostate cancer.

Acknowledgements: This study was supported by Pilot funds for Technology Transfer from Science and Technology Bureau of Changsha (No. K0904151-11).

\section{References}

[1] WILSON KM, GIOVANNUCCI EL, MUCCI LA. Lifestyle and dietary factors in the prevention of lethal prostate cancer. Asian J Androl. 2012; 14: 365-374. http://dx.doi.org/10.1038/ aja.2011.142

[2] GUMULEC J, MASARIK M, KRIZKOVA S, HLAVNA M, BABULA P, et al. Evaluation of alpha-methylacyl-CoA racemase, metallothionein and prostate specific antigen as prostate cancer prognostic markers. Neoplasma. 2012; 59: 191-201. http: //dx.doi.org/10.4149/neo 2012025

[3] SIVONOVA MK, DOBROTA D, MATAKOVA T, DUSENKA R, GROBARCIKOVA S, et al. Microsomal epoxide hydrolase polymorphisms, cigarette smoking and prostate cancer risk in the Slovak population. Neoplasma. 2012; 59: 79-84. http: //dx.doi.org/10.4149/neo 2012010
[4] JAMASPISHVILI T, SCORILAS A, KRAL M, KHOMERIKI I, KURFURSTOVA D, et al. Immunohistochemical localization and analysis of kallikrein-related peptidase 7 and 11 expression in paired cancer and benign foci in prostate cancer patients. Neoplasma. 2011; 58: 298-303.

[5] LI Y, YUAN H, YANG K, XU W, TANG W, et al. The structure and functions of P-glycoprotein. Curr Med Chem. 2010; 17: 786-800. http: //dx.doi.org/10.2174/092986710790514507

[6] ZUBERCOVA O, BABUSIKOVA O. The multidrug resistance in human leukemias. Neoplasma. 1998; 45: 53-59.

[7] EICHHORN T, EFFERTH T. P-glycoprotein and its inhibition in tumors by phytochemicals derived from Chinese herbs. J Ethnopharmacol. 2012; 141: 557-570. http: //dx.doi. org/10.1016/j.jep.2011.08.053

[8] LIU Q. Triptolide and its expanding multiple pharmacological functions. Int Immunopharmacol. 2011; 11: 377-383. http: //dx.doi.org/10.1016/j.intimp.2011.01.012

[9] ZHU W, LI J, WU S, LI S, LE L, et al. Triptolide cooperates with Cisplatin to induce apoptosis in gemcitabine-resistant pancreatic cancer. Pancreas. 2012; 41: 1029-1038. http: //dx.doi.org/10.1097/MPA.0b013e31824abdc0

[10] LIU Y, SONG F, WU WK, HE M, ZHAO L, et al. Triptolide inhibits colon cancer cell proliferation and induces cleavage and translocation of 14-3-3 epsilon. Cell Biochem Funct. 2012; 30: 271-278. http: //dx.doi.org/10.1002/cbf.2793

[11] LI CJ, CHU CY, HUANG LH, WANG MH, SHEU LF, et al. Synergistic anticancer activity of triptolide combined with cisplatin enhances apoptosis in gastric cancer in vitro and in vivo. Cancer Lett. 2012; 319: 203-213. http: //dx.doi. org/10.1016/j.canlet.2012.01.006

[12] XIAOWEN H, YI S. Triptolide sensitizes TRAIL-induced apoptosis in prostate cancer cells via p53-mediated DR5 upregulation. Mol Biol Rep. 2012; 39: 8763-8770. http: //dx.doi. org/10.1007/s11033-012-1737-2

[13] DAI CL, LIANG YJ, CHEN LM, ZHANG X, DENG WJ, et al. Sensitization of ABCB1 overexpression cells to chemotherapeutic agents by FG020326 via binding to $\mathrm{ABCB} 1$ and inhibiting its function. Biochem Pharmacol 2009; 78: 355-364. http: //dx.doi.org/10.1016/j.bcp.2009.04.023

[14] OZKAYA S, FINDIK S, ATICI AG, DIRICA A. Cisplatin-based chemotherapy in elderly patients with advanced stage (IIIB and IV) non-small cell lung cancer patients. Neoplasma 2011; 58: 348-351. http: //dx.doi.org/10.4149/neo $2011 \quad 04 \quad 348$

[15] OZKAN M, BERK V, KAPLAN MA, BENEKLI M, COSKUN $\mathrm{U}$, et al. Gemcitabine and cisplatin combination chemotherapy in triple negative metastatic breast cancer previously treated with a taxane/anthracycline chemotherapy; multicenter experience. Neoplasma 2012; 59: 38-42. http: //dx.doi.org/ $\underline{10.4149 / \text { neo } 2012 \quad 005}$

[16] STACEY DW. CYCLIN D1 serves as a cell cycle regulatory switch in actively proliferating cells. Curr Opin Cell Biol. 2003; 15: 158-163. http: //dx.doi.org/10.1016/S09550674(03)00008-5

[17] HUANG W, ZHANG H, ZOU K, CHEN J, LI X, et al. Total saponins of Tupistra chinensis induces apoptosis in A549 cells. Neoplasma 2012; 59: 613-621. http: //dx.doi.org/10.4149/ neo 2012078 
[18] CHEN YW, LIN GJ, CHUANG YP, CHIA WT, HUENG DY, et al. Triptolide circumvents drug-resistant effect and enhances 5-fluorouracil antitumor effect on KB cells. Anticancer Drugs. 2010; 21: 502-513. http: //dx.doi.org/ 10.1097/CAD.0b013e328337337c

[19] LI H, HUI L, XU W, SHEN H, CHEN Q, et al. Modulation of P-glycoprotein expression by triptolide in adriamycin-resistant K562/A02 cells. Oncol Lett. 2012; 3: 485-489.

[20] LIN X, ZHANG X, WANG Q, LI J, ZHANG P, et al. Perifosine downregulates MDR1 gene expression and reverses multidrug-resistant phenotype by inhibiting PI3K/Akt/NF$\kappa \mathrm{B}$ signaling pathway in a human breast cancer cell line.
Neoplasma. 2012; 59: 248-256. http: //dx.doi.org/10.4149/ neo 2012032

[21] KIM MJ, LEE TH, KIM SH, CHOI YJ, HEO J, et al. Triptolide inactivates Akt and induces caspase-dependent death in cervical cancer cells via the mitochondrial pathway. Int J Oncol. 2010; 37: 1177-1185. http: //dx.doi.org/10.3892/ ijo 00000769

[22] YOSHIDA N, TAKAGI A, KITAZAWA H, KAWAKAMI J, ADACHI I. Inhibition of P-glycoprotein-mediated transport by extracts of and monoterpenoids contained in Zanthoxyli fructus. Toxicol Appl Pharmacol 2005; 209: 167-173. http: //dx.doi.org/10.1016/j.taap.2005.04.001 